\title{
The Predicting Effects of Self-Efficacy, Self-Esteem and Prior Travel Experience on Sociocultural Adaptation Among International Students
}

\author{
Werede Tareke Gebregergis \\ Desbele Tekie Mehari \\ Dawit Yikealo Gebretinsae \\ Aster Habte Tesfamariam \\ Central China Normal University, the People's Republic of China \\ Asmara College of Education, Eritrea
}

\begin{abstract}
Personal and situational factors contribute to international students' sociocultural adjustment in a host society. Thus this study attempts to determine the roles of selfefficacy, self-esteem, and previous travel experience on sociocultural adjustment. The sample for this study constituted 328 undergraduate and postgraduate international students, studying in three Chinese universities. Participants completed a set of tests measuring their sociocultural adjustment, self-efficacy and self-esteem, as well as answered demographic questions. Hierarchical multiple regression and a PROCESS macro were used to analyze the data. Results revealed that prior travel experience, self-efficacy, and self-esteem significantly predicted sociocultural adaptation. In particular, self-esteem partially mediated the relationship between self-efficacy and sociocultural adaptation. Limitations and future study directions and implications for the findings are discussed.
\end{abstract}

Keywords: international students, self-efficacy, self-esteem, sociocultural adaptation 


\section{INTRODUCTION}

Globalization has increased opportunities for cross-cultural interactions between societies of various countries of the world. Many organizations, especially multinational companies, send employees to work as expatriates in their overseas branches. Universities are also adjusting to the trend of globalization and have been recruiting students from abroad. For instance, as cited in Baohua and Ewan (2016), the United Nations Educational, Scientific and Cultural Organization (2014) report shows that international students' mobility has expanded at a rapid rate since the turn of the 21 st century.

Internationalization in higher learning education has become an increasingly important issue in most countries around the world (Mustaffa \& Ilias, 2013). In western countries, various studies have identified the types and nature of adjustment problems that international students commonly face in their academic journey (Dzansi \& Monnapula-Mapesela, 2012). There can be some complications in adjustment for foreigners in the host society regardless of the reasons behind them.

Many researchers agree that international students face a variety of sociocultural adaptation challenges while studying in the host countries (Garcia, 2015; Gebhard, 2012; Mesidor \& Sly, 2016; Wilson, 2013). These scholars have identified specific problems and discovered behavioral pattern of students who face with these adjustment problems. For instance, Garcia (2015) noted that the inability to adjust to a new environment might devastate the psychological well-being of the individuals, which may elicit academic failure or social problems. A lengthy intercultural adjustment time may lead to the students' study termination or increase their time to graduation (Garcia, 2015).

Many studies have identified three overlying problems that international students face, including difficulties with academics, social interaction, and handling emotions (Gebhard, 2012; Mesidor \& Sly, 2016). Similarly, Wang et al. (2014) also indicated that international students were more prone to adjustment difficulties when they enter colleges. Various factors contribute to the academic, social, cultural, and psychological adjustment of international students. Sociocultural adjustment challenges, in particular, describe how students adapt to another culture (Gebhard, 2012). Failure to adjust to a new culture has an unpleasant psychological effect on the individual that could either result in academic challenges or social maladjustment (Garcia, 2015). Drawing on these adjustment difficulties, several studies have attempted to examine the role of situational and individual difference domains on the sociocultural adjustment. These studies suggested that both domains of variables can explain the variance in the sociocultural adaptation (Wilson, 2013; Zhang \& Goodson, 2011).

Drawing on the limited sociocultural studies on the international students studying in China (Liu, et al., 2016; Ngwira, et al., 2015; Wen, et al., 2017), the present study attempted to address the research gap by examining the sociocultural adaptation of international students in the context of individual difference factors. More specifically, the primary goal of this study was to uncover the relationships of self-efficacy, self-esteem, and prior travel experience with sociocultural adaptation among international university students studying in China. Information related to the 
nature of relationships between the study variables may contribute to the scientific understanding of cultural transition. It might also pave the way for host university communities to better deal with the sociocultural adjustment difficulties of their fellow students.

\section{Hypotheses}

Based on the reviewed literature and theoretical conceptualization, the following guiding hypotheses were propounded for the study.

H1: Students' prior travel experience is positively related to sociocultural adaptation.

H2: Students with high levels of self-efficacy have better sociocultural adaptation.

H3: Students with high levels of self-esteem have better sociocultural adaptation.

H4: Students' self-esteem mediates the relationship between their selfefficacy and sociocultural adaptation.

\section{LITERATURE REVIEW}

\section{Sociocultural Adaptation}

In the general field of acculturation, cross-cultural adaptation can best be conceptualized into two separate but interconnected spheres: psychological and sociocultural adjustment (Searle \& Ward, 1990). Psychological adjustment refers to the affective or emotive aspect of adjustment outcomes such as psychological wellbeing, satisfaction, and depression whereas sociocultural adjustment stresses the behavioral aspect of the intercultural transition (Ward \& Kennedy, 1994; Ward \& Rana-Deuba, 1999). These two domains of cross-cultural adjustment require different theoretical approaches. Psychological adjustment is grounded on psychological stress, and within a coping paradigm, whereas sociocultural adjustment is best framed within a cultural learning approach (Ward, et al., 2005).

According to culture learning theory, sociocultural difficulties stem from sojourners, immigrants, or refugees' limited capacity to deal with daily social encounters effectively. A cultural learning perspective centers on the assumptions that individuals face intercultural complications when they lack the required sociocultural skills to appropriately function in the multicultural environment (Masgoret \& Ward, 2006). Therefore, individuals are required to obtain and develop culture-specific behavioral and social skills to handle these difficulties and better respond to cultural demands. A cultural learning perspective mainly involves knowledge and an understanding of intercultural communications such as verbal and nonverbal components, as well as rules, conventions, and norms and their contributions to the success of sociocultural adjustment and competence (Ward \& Kennedy, 1994). 
Although Ward and Kennedy (1994) argued that contextual variables best predict people's sociocultural adaptation, it is also important to consider that several individual variables predict both psychological and sociocultural domains of intercultural transition (Wilson, 2013; Zhang \& Goodson, 2011) because they are interlinked to one another. Cross-cultural researchers assert that intercultural adjustment is a complex and multidimensional process influenced by multiple factors and no single personal situational variable determines the adjustment outcome (Mesidor \& Sly, 2016; Smith \& Khawaja, 2011). Therefore, both situational and individual difference variables can affect the cultural learning process and behavioral competence of acculturating individuals. There are abilities that individuals bring with them before coming to the arena of acculturation that affect their cultural transition (Berry, 1997). Specifically, some studies on the relationship between individual difference factors and sociocultural adaptation have documented that personal factors such as cultural self-efficacy, cultural intelligence, emotional intelligence, personality, and coping, play an essential role in sociocultural adjustment (Wilson, 2013; Zhang \& Goodson, 2011). Similarly, general self-efficacy (Bandura, 1995) and self-esteem (Kernis, 2003) are thought to be part of the individual's coping resources that facilitate cultural learning and development of behavioral competence of sojourners.

\section{Self-Efficacy and Sociocultural Adaptation}

Self-efficacy refers to "belief in one's capabilities to organize and execute the course of action required to manage the prospective situation" (Bandura, 1997, p. 2). People's motives, emotional states, and behaviors are the product of their beliefs, not an objective evaluation of the context (Bandura, 1995). According to social learning theory, self-efficacy is explicitly associated with individuals' competency and their capacity to deal with environmental demands. It is also related to personal agency in the sense that people's beliefs about their determination and enthusiasm directly impact the outcome of their actions (Bandura, 1995).

Self-efficacy has been also conceptualized globally as an individual's consistent capability to effectively function in a wide range of stressful contexts (Schwarzer, 1992). Therefore, from these definitions, it can be inferred that self-efficacy can perform the same function in the context of sociocultural adjustment of international students. When students believe that they possess the capabilities to better fit into the host community, they can achieve better sociocultural adaptation. Several scholars have also claimed that highly self-efficacious individuals appear to be goal-oriented, conscientious, indomitable, and adaptable (Bandura, 1995; Poyrazli, et al., 2002; Schwarzer, 1992).

Cross-cultural studies have supported the premise that there is a positive relationship between self-efficacy and sociocultural adjustment. For example, Yusoff (2011) examined the relationship between self-efficacy, social support, and sociocultural adjustment among 185 international students in Malaysia. The study revealed that self-efficacy positively and significantly predicted a high level of cultural empathy during sociocultural adjustment. In another study, Poyrazli et al. (2002) surveyed 122 international students and found that students' assertiveness, 
English language proficiency, and academic self-efficacy positively predicted their general intercultural adjustment.

Further, Hechanova-Alampay et al. (2002) carried out a longitudinal study on predictors of adjustment and strain among international and domestic students. Their results revealed that self-efficacy, social support, and cultural novelty predicted the students' adjustment and strain. Students with a high level of confidence (selfefficacy) were found to have better adjustment and less strain. Mesidor and Sly (2016) also noted that students with a high level of self-efficacy have better interpersonal relationships and academic performance. Similarly, Telbis et al., (2014) also reported that students with high self-efficacy were found to complete their program of study and were confident in utilizing their coping resources to effectively function during their cultural transition. Students with low self-efficacy were, however, found to be less confident in coping with sociocultural adaptation, language difficulty, academic ability, and financial difficulties.

\section{Self-Esteem and Sociocultural Adaptation}

Self-esteem is another psychological factor that affects people's sociocultural adjustment. Self-esteem refers to the global feeling of self-worth or self-regard (Bosson \& Swann, 2009). It was also defined as people's favorable or unfavorable feeling about themselves (Rosenberg, 1965). Self-esteem is thought to be a relatively permanent personal characteristic that integrates both motivational and cognitive aspects. Generally, people are motivated to engage themselves in different activities to achieve a sense of self-worth and competence.

Individuals with a high level of self-esteem tend to put in a continuous effort to enhance their feeling of self-worth (Kernis, 2003). People with healthy self-esteem or positive self-evaluation are also considered to be goal-oriented and deterministic. They mobilize their resources and vigorously work to translate their desires into actions that respond to their esteem needs (Deci \& Ryan, 1995). From this perspective, it can be deduced that self-esteem may have a significant impact on student sojourners' intercultural transition in a way that those with high levels of selfesteem may experience minimal sociocultural adjustment (Yang et al., 2006).

On the contrary, individuals with low self-esteem appear to be defensive, avoid social relations, and contribute less to their interpersonal relationships (Dong et al., 2008; Sternberg \& Vroom, 2002). Further, Dong et al. (2008) suggested that selfesteem, as an agent, inspires people to appreciate cultural diversity and learn about cultural variation and commonalities. Researchers have found that while high selfesteem is associated with acceptance, low self-esteem is associated with rejection in the arena of interpersonal relationships (Baldwin et al., 2004; Koch, 2002). Additionally, in a study conducted by Yang et al. (2006), highly confident international students were also found to have higher self-esteem and fewer adjustment difficulties. Some studies have further delved into the mediating role of self-esteem on the relationship between individual variables and intercultural adjustment. For instance, after surveying 271 undergraduate students, Nordstrom et al. (2014) provided evidence for the mediating effect of self-esteem on the interplay between social anxiety and academic and institutional adjustment. 
Although several studies generally suggest that self-esteem is a critical component of sociocultural adaptation, some studies have not indicated a significant relationship between self-esteem and sociocultural adaption. For instance, Tchoh and Mertan (2018) conducted a cross-sectional study to explore the relationship between self-construal, social support, self-esteem, and sociocultural adaptation with a sample of 112 students from Sub-Saharan African countries. Their results revealed that while self-construal and social support were found to be significant predictors, self-esteem was found to have a nonsignificant predicting effect on sociocultural adaptation. Deci and Ryan (1995) also underscored that the situational and interpersonal variables and their deterministic nature with self-esteem need further attention. They also noted the need for the full exploration of the role of self-esteem in people's continuous endeavors to deal with the challenges and opportunities for day-to-day activities.

\section{Prior Travel Experience and Sociocultural Adaptation}

Following the cultural learning model, previous studies have identified many situational factors that affect the nature of cross-cultural contact and transition of sojourners, immigrants, or refugees. Factors such as cultural knowledge (Li \& Gasser, 2005; Ward \& Kennedy, 1999), length of stay in the host community, host language proficiency (Ward \& Kennedy, 1994, 1999), identification, and interaction with local individuals (Brisset et al., 2010; Li \& Gasser, 2005) were found to predict sociocultural adaptation. Another salient contextual factor that is believed to contribute to the success of sociocultural adaptation is prior travel experience. Those with international prior travel experience before arriving in the host community have better intercultural interaction and adjustment (Searle \& Ward, 1990) because of their clear expectations and psychological readiness for the adjustment difficulties (Black et al., 1991). Similarly, several international student studies have documented that previous travel exposure is significantly related to intercultural competence (Goldstein \& Kim, 2006; Mustaffa \& Ilias, 2013).

Based on the reviewed literature, it can generally be said that the potential influence of the individual factors on sociocultural adaptation is evident (Ang \& VanDyne, 2008; Bandura, 1997; Berry, 1997; Dong et al., 2008; Wilson, 2013). However, the attention of the majority of the empirical studies has long been on situational factors, and subsequently, studies on individual different factors and sociocultural adjustment were significantly limited and underrepresented (Wilson, 2013). Similarly, several researchers have voiced that a comprehensive understanding of the process of acculturation calls for the consideration of the input of both individual and situational variables (Berry, 1997; Padilla \& Perez, 2003).

\section{METHODS}

\section{Sample and Data Collection Procedure}

The present study recruited international students $(N=328)$ who arrived in China to pursue their undergraduate and postgraduate studies. The participants were conveniently selected from three Chinese universities located in Wuhan, Hubei 
province. In the process of data collection, we distributed self-reporting questionnaires to the participants in their respective classrooms, dormitories, and campus libraries. We assured the respondents that the data would be kept confidential and also would not be used for any purpose other than the study. Participation in the study was, therefore, voluntary.

As presented in Table 1, participants of the study were heterogeneous in their demographic characteristics. The study comprised of $200(61 \%)$ male and $128(39 \%)$ female participants with the mean age of 26.77 and average length of stay in China of 18.85 months. The majority of participants were not married $(n=259 ; 79 \%)$. The educational level or degrees of the respondents were bachelor's $(n=106 ; 32 \%)$, master's $(n=141 ; 43 \%)$, and doctorate $(n=81 ; 25 \%)$. The majority were from Africa $(n=141 ; 43 \%)$, Asia $(n=133 ; 41 \%)$, a small number from Europe $(n=36 ; 11 \%)$ and a few from Oceania, Latin America, and North America $(n=18 ; 5 \%)$. As part of the demographic question items, we also included a question whether or not students have had previous international travel experience. Two hundred (61\%) participants reported that they had previous travel exposure before coming to China, whereas 128 (39\%) reported that it was their first experience to reside abroad.

Table 1: Frequency Distribution of Characteristics of the Participants

\begin{tabular}{lcc}
\hline Variable & $n$ & $\%$ \\
\hline Gender & 200 & 61 \\
Male & 128 & 39 \\
Female & & \\
Marital status & 69 & 21 \\
$\quad$ Married & 259 & 79 \\
$\quad$ Unmarried & & \\
Education & 106 & 32 \\
Bachelor's & 141 & 43 \\
Master's & 81 & 25 \\
Doctorate & & \\
Continent & 141 & 43 \\
Africa & 133 & 41 \\
Asia & 36 & 11 \\
Europe & 18 & 5 \\
Other & & \\
Travel experience & 200 & 39 \\
$\quad$ Yes & 128 & \\
No & &
\end{tabular}




\section{Measures}

\section{Sociocultural Adaptation}

The revised version of the Sociocultural Adaptation Scale (SCAS-R) developed by Wilson (2013) was applied to measure the sociocultural adjustment or competence of the students. It is a 21 item self-report questionnaire based on a Likert-type of scale ranging between 1 (Not at all competent) and 5 (Extremely competent). The scale has five subscales: interpersonal communication (seven items), academic work/performance (four items), personal interests and community involvement (four items), ecological adaptation (four items), and language proficiency (two items). The range of the total computed scores is 21-105. Higher scores represent higher behavioral competence or sociocultural adaptation. Scores can also be computed for each domain or subscale (Wilson, 2013). SCAS-R was found to be a highly reliable instrument with Cronbach's alpha of .92 (Wilson, 2013). Similarly, in the present sample data, the scale showed high internal consistency $(\alpha=.85)$.

\section{Self-Efficacy}

The General Self-Efficacy Scale authored by Schwarzer and Jerusalem (1995) was employed to assess the self-efficacy of the participants. It was developed as a one-dimensional scale devised to evaluate people's beliefs in their capabilities to accomplish a particular task. The measure is a self-report based on a Likert-type of scale ranging from 1 (Not at all true) to 4 (Exactly true). Item values are calculated to yield a total score in which the range falls between 10 and 40. High scores indicate high self-efficacy. Previous studies found the scale to be valid and highly reliable with a reliability coefficient alpha ranging from .70 to .90 (Hajloo, 2014). The calculated Cronbach's alpha value of the measure in the present study was .82 .

\section{Self-Esteem}

To measure the variable of self-esteem, Rosenberg's (1965) Self-Esteem Scale was used. The scale is a unidimensional, widely used self-report instrument devised to assess individuals' global feeling of self-worth or self-acceptance. It comprises 10 items on four Likert scales with the range of 1 (Strongly disagree) and 4 (Strongly agree). The sums of the scores range from 10 to 40 with higher scores indicating a high level of self-esteem. The measure is a valid and reliable instrument, and its internal consistency ranges from .77 to .88 . In the present study, the measure was found to maintain a good internal consistency $(\alpha=.80)$

\section{Data Analyses}

After inputting of the data into SPSS Version 25, we used descriptive statistics such as mean and standard deviation to summarize the data. Then, we performed the Pearson product-moment correlation to explore the bivariate relationships between study variables. Next, we conducted a hierarchical multiple regression analyses to determine the predicting effects of self-efficacy, self-esteem, and prior travel 
experience on sociocultural adaptation while controlling the sociodemographic variables of age, gender, marital status, and length of stay. Finally, a regression PROCESS macro was run to test the mediation effect.

\section{RESULTS}

\section{Descriptive Statistics of Study Variables}

The values of mean, standard deviation, Cronbach's alpha, a measure of shape distribution (skewness and kurtosis) are summarized in Table 2. The reliability coefficients for all the study variable appeared to be high and greater than the baseline value of .70 (George \& Mallery, 2003). The underlying assumption of normality for the data sets was checked using the calculated values of skewness and kurtosis measure of shape distribution. The range for the acceptable limit of skewness and kurtosis is from -2 to +2 (Gravetter \& Wallnau, 2014). The values for the study variables came to fall within this acceptable range, ensuring that the data were normally distributed.

Table 2: Descriptive Statistics of the Study Variables

\begin{tabular}{lcccccc}
\hline Variables & $M$ & $S D$ & Items & $\alpha$ & Sk & $\mathrm{Ku}$ \\
\hline Self-efficacy & 31.94 & 4.44 & 10 & .82 & -0.64 & 1.41 \\
Self-esteem & 31.03 & 5.35 & 10 & .80 & -0.36 & -0.30 \\
Sociocultural adaptation & 71.22 & 11.04 & 21 & .85 & -0.35 & 0.30 \\
\hline
\end{tabular}

Note. $\mathrm{Sk}=$ skewness; $\mathrm{Ku}=$ kurtosis.

\section{Bivariate Relationships Between Study Variables}

Table 3 depicts the coefficient values for the bivariate relationships between the study variables. Results from Pearson's product-moment correlation revealed a significant correlation between all the major study variables (self-efficacy, selfesteem, and sociocultural adaptation). Both self-efficacy and self-esteem showed significant relationship with sociocultural adaptation $(r=.45, p<.01 ; r=.30, p<$ $.01)$. The correlation between self-esteem and self-efficacy was significant as well $(r$ $=.43, p<.01)$. In addition, as expected, students' previous travel experience showed a significant relationship with sociocultural adaptation $(r=.14, p<.01)$. 
Table 3: Intercorrelations Between the Study Variables

\begin{tabular}{lccccccc}
\hline Variable & 1 & 2 & 3 & 4 & 5 & 6 & 7 \\
\hline Gender & & & & & & & \\
Age & $.29^{* *}$ & & & & & & \\
Marital status & $.18^{* *}$ & $.63^{* *}$ & & & & & \\
$\quad \begin{array}{l}\text { Travel } \\
\quad \text { experience }\end{array}$ & $-.17^{* *}$ & .02 & .03 & & & & \\
$\quad$ & & & & & & & \\
Length of stay & .05 & -.03 & $-.14^{*}$ & -.02 & & & \\
Self-efficacy & .05 & $.15^{* *}$ & .10 & .05 & .03 & & \\
$\quad$ Self-esteem & .02 & .01 & -.04 & -.03 & .05 & $.43^{* *}$ & \\
$\begin{array}{l}\text { Sociocultural } \\
\quad \text { adaptation }\end{array}$ & -.04 & -.08 & .00 & $.14^{*}$ & .09 & $.45^{* *}$ & $.30^{* *}$ \\
${ }^{*} p \leq .05$ (2-tailed); ${ }^{* *} p \leq .01$ (2-tailed). & & & & &
\end{tabular}

\section{Predictors of Sociocultural Adaptation}

The main purpose of these analyses was to determine the predicting effects of self-efficacy and self-esteem on the level of sociocultural adaptation while controlling the demographic factors. In doing so, three blocks of the hierarchical multiple regression model were developed. The first block of the regression contained sociodemographic variables (gender, age, marital status, length of stay, and previous travel experience). Then, self-efficacy was put into the second block. Finally, selfesteem was inputted into the third block of the regression model. The results presented (as displayed in Table 4) indicated that variables in the first block of the model jointly explained a small percent $(4 \%)$ of the variance in sociocultural adaptation, albeit the model was significantly different from zero $\left(R^{2}=0.04, F[5,321]\right.$ $=2.67, p<.05)$. Out of all the sociodemographic variables, students' age and previous travel experience were found to have significant unique predicting effects on their sociocultural adjustment. Younger students $(\beta=-0.14, p<.05)$ as well as students with previous travel exposure $(\beta=0.29, p<.001)$ showed better sociocultural adjustment. The addition of self-efficacy into the second block of the model greatly improved the ability of the model to explain $25 \%$ of the variance in the dependent variable $\left(R^{2}=0.25, F[6,320]=17.38, p<.001\right)$. When effects for the sociodemographic factors were controlled, self-efficacy explained $21 \%$ of the variance in the criterion variable and the model was statistically significant $\left(R^{2}\right.$ change $=.21, F$ change $[1,320]=87.35, p<.001)$. Highly self-efficacious students reported better sociocultural adaption $(\beta=0.46, p<.001)$. Age and previous travel experience remained to have significant effects on the outcome variable in the second block as well.

When self-esteem was included in the third block of the model, the outcome variable regressed by $26 \%$ of variance and the model was significantly different from zero $\left(R^{2}=0.26, F[7,319]=16.05, p<.001\right)$. However, after controlling the effects for self-efficacy and demographics, self-esteem accounted for by a small percent $(2 \%)$ of the variance in the sociocultural adaptation, and the regression model was statistically significant $\left(R^{2}\right.$ change $=0.02, F$ change $\left.[1,319]=6.32, p<.05\right)$. Students 
with high self-esteem had better performance in their sociocultural adaption $(\beta=0.14$, $p<.05$ ). Age and prior travel experience from the Block 1 variables and self-efficacy of Block 2 also continued to be significant predictors of the outcome variable in Block 3 of the model.

\section{Table 4: Hierarchical Regression Results for Predictors of Sociocultural Adaptation}

\begin{tabular}{|c|c|c|c|c|c|c|c|c|}
\hline \multirow[b]{2}{*}{ Predictors } & \multirow[b]{2}{*}{ B } & \multirow[b]{2}{*}{ SEB } & \multirow[b]{2}{*}{$\beta$} & \multicolumn{5}{|c|}{ Model } \\
\hline & & & & $R$ & $R^{2}$ & $\Delta R^{2}$ & $\Delta F$ & $d f$ \\
\hline Block 1 & & & & 0.20 & 0.04 & & $2.67^{*}$ & 5,321 \\
\hline Gender & -0.13 & 1.32 & -0.01 & & & & & \\
\hline Age & -0.27 & 0.13 & $-0.14^{*}$ & & & & & \\
\hline Marital status & 2.83 & 1.92 & 0.10 & & & & & \\
\hline $\begin{array}{l}\text { Travel } \\
\quad \text { experience }\end{array}$ & 3.13 & 1.26 & $0.14^{*}$ & & & & & \\
\hline Length of stay & 0.06 & 0.04 & 0.10 & & & & & \\
\hline Block 2 & & & & 0.50 & 0.25 & 0.21 & $17.38^{* * *}$ & 6,320 \\
\hline Gender & -0.26 & 1.17 & -0.01 & & & & & \\
\hline Age & -0.38 & 0.12 & $-0.21^{* *}$ & & & & & \\
\hline Marital status & 2.63 & 1.71 & 0.10 & & & & & \\
\hline $\begin{array}{l}\text { Travel } \\
\quad \text { experience }\end{array}$ & 2.59 & 1.12 & $0.11^{* *}$ & & & & & \\
\hline Length of stay & 0.06 & 0.03 & 0.09 & & & & & \\
\hline Self-efficacy & 1.15 & 0.12 & $0.46^{* * *}$ & & & & & \\
\hline Block 3 & & & & 0.51 & 0.26 & 0.02 & $16.05^{* * *}$ & 7,319 \\
\hline Gender & -0.28 & 1.16 & -0.01 & & & & & \\
\hline Age & -0.38 & 0.12 & $-0.20^{* *}$ & & & & & \\
\hline Marital status & 2.87 & 1.70 & 0.11 & & & & & \\
\hline $\begin{array}{l}\text { Travel } \\
\quad \text { experience }\end{array}$ & 2.71 & 1.11 & $0.12^{*}$ & & & & & \\
\hline Length of stay & 0.05 & 0.03 & 0.08 & & & & & \\
\hline Self-efficacy & 1.00 & 0.14 & $0.40^{* * *}$ & & & & & \\
\hline Self-esteem & 0.28 & 0.11 & $0.14^{*}$ & & & & & \\
\hline
\end{tabular}

Note. Dummy variables were coded as: Gender: Male $=1$, Females $=0$; Marital status: Married $=1$, Unmarried $=0$; Prior travel experience: $\mathrm{Yes}=1$, No $=0 .{ }^{*} p<$ $.05,{ }^{* *} p<.01,{ }^{* * *} p<.001$

\section{Mediation Analyses}

\section{Mediating Effect of Self-esteem}

The intermediary effect of self-esteem on the relationship between self-efficacy and sociocultural adaptation was further explored. Baron and Kenny (1986) proposed four conditions that define the presence of mediating effects. First, the independent variable must predict the dependent variable. Second, there must be a significant relationship between the independent variable and the presumed mediator. Third, the mediator must also significantly predict the dependent variable. Finally, when the 
mediator is removed from the model, the significant predicting effect of the independent variable on the dependent variable must either be reduced (partial mediation) or eliminated (full mediation).

In this context, the output of the regression PROCESS macro of this study demonstrated that all four conditions were satisfied, indicating that mediation occurred. The independent variable of self-efficacy was found to have a significant positive effect on the dependent variable of sociocultural adaption $(b=1.11, t=9.02$, $p<.001)$ and the mediating variable of self-esteem $(b=0.52, t=8.54, p<.001)$. In addition, self-esteem significantly predicted sociocultural adaption $(b=0.28, t=2.50$, $p<.05$ ). When self-esteem was controlled, the predicting ability of self-efficacy was weakened but continued to be significant $(b=0.97, t=7.15, p<.001)$. To test the significance of the indirect effect, a bootstrap estimation approach with the sample of 5,000 was used, and the indirect effect was evident in which the $95 \%$ confidence interval did not include zero $(b=0.15, S E=.06,95 \% C I=[0.03,0.28])$.

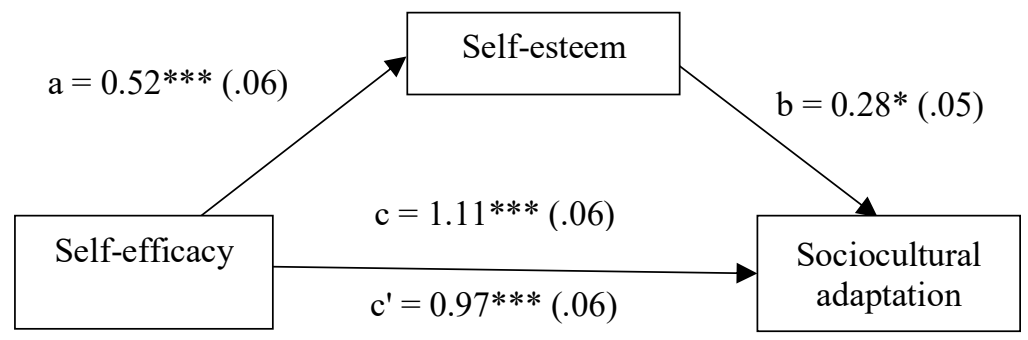

Figure 1: Unstandardized Coefficients for the Regression Paths

Note. (Paths a, $\mathrm{b}$ and $\mathrm{c}$ ) Between the Independent, Mediator, and Dependent Variables with Standard Errors in Parentheses. ${ }^{*} p<.05,{ }^{* * *} p<.001$. The indirect effect is $(0.52)(0.28)=0.15$.

\section{DISCUSSION}

The main purpose of this study was to discover the predicting influences of selfefficacy, self-esteem, and prior travel experience on sociocultural adaptation of international students studying in China. The study also tested the indirect effect of self-efficacy on sociocultural adaptation through self-esteem. The regression output indicated that all the predictors significantly impacted the level of sociocultural adaptation, and the mediating effect for self-esteem was evident as well.

Drawing on the theoretical assumption of cultural learning theory, this study, in its first hypothesis, expected that prior travel experience would have a significant positive contribution to sociocultural adjustment. The sample data supported this hypothesis, as students who had travel experience before arriving in China reported better sociocultural adaption than the students with no prior intercultural exposure. The finding might be better explained in the context of a cultural learning approach. 
According to culture learning theory, individuals need to learn and develop appropriate social and behavioral skills that enable them to effectively function in the new sociocultural environment (Ward et al., 2005). In this sense, it looks plausible that people with previous international exposure can make the best advantage of their previous experience in learning the necessary cultural information. For instance, their previous experience about the influence of cultural variation in both verbal and nonverbal interpersonal communication might aid them to develop a sense of intercultural sensitivity and make the necessary amendments in their social interaction. Besides previous travel experience might allow individuals to be wellprepared for the challenges that may be encountered during the intercultural transition that might otherwise be shocking (Black et al., 1991). In agreement with the present finding, several previous studies have also asserted that previous travel experience accelerated sociocultural adaptation (Goldstein \& Kim, 2006; Searle \& Ward, 1990).

The present sample data confirmed the second hypothesis of the study that students' self-efficacy would positively and meaningfully associate with their sociocultural adaptation scores. The study indicated that international students' strong belief in their capacity is a driving factor in the accomplishment of intercultural adjustment. Self-efficacious individuals are believed to be highly motivated and passionate to actively participate in a wide range of academic and community activities, which raises their intercultural consciousness and adaptive behaviors. Although the host environment may encompass a broad range of challenges, selfefficacious students remain confident to believe in the power of their resources to effectively deal with challenges and learn the necessary behavioral skills. Social learning theory postulates that self-efficacy is closely associated with the development of behavior competence or skill in the context of deterministic interaction between the person and the environment (Bandura, 1995). People with a higher level of self-efficacy appear to set high standard goals and show greater resilience and effort in the realization of the goals irrespective of the toughness of the task or condition. People with low self-efficacy, on the other hand, function in the opposite way. They prefer low standards and easily manageable tasks and show less perseverance in the face of difficulties (Bandura, 1997; Jex \& Britt, 2008). The findings of this study are consistent with the report of several past cross-cultural studies that self-efficacy is positively and significantly related to sociocultural adjustment (e.g., Mesidor \& Sly, 2016; Poyrazli et al., 2002; Yusoff, 2011).

Third, the study also hypothesized that self-esteem would positively predict sociocultural adaptation. Supporting this hypothesis, the regression results of this study revealed that self-esteem scores were positively related to sociocultural adaptions scores. This indicates that students with higher level of self-esteem are observed to have a better sociocultural adjustment to the host environment. The reason for this might be attributed to the assumption that the overall sense of selfworth, personal value, and how much an individual appreciates, esteems, and values themselves, has a significant contribution to achievement in life. Thus, it seems conceivable that international students with high levels of self-esteem can show a great level of interest and motivation in their social interactions with people of different cultures and improve their multicultural competence. On the other hand, international students who do not feel themselves worthy might experience feelings 
of inner doubt and self-loathing. This negative evaluation of self can make the students avoid social activities and have poor or limited social relationships, which may be a great hindrance for the success of their sociocultural adaptation. In line with this statements, Dong et al. (2008) pronounced that unlike individuals with high selfesteem who are motivated, confident, and active in interpersonal communications, individuals with poor self-esteem tend to be self-locked, defensive, and contribute less to social relations.

Similarly, previous studies reveal that self-esteem is positively associated with acceptance and negatively associated with rejection in social relations (Baldwin et al., 2004; Koch, 2002). Cultural learning theory also posits that learning behavioral skills is a crucial feature of successful sociocultural adjustment. Self-esteem as a motivational aspect, therefore, plays a significant role in the process of learning the necessary adaptive behaviors. Although our findings, together with several previous studies, are in favor of the positive contribution of self-esteem to adjustment, the study of Tchoh and Mertan (2018) failed to detect the role of self-esteem in sociocultural adaption. This variation might be associated with methodological differences or sample size.

Fourth, the study hypothesized that self-esteem would mediate the relationship between self-efficacy and sociocultural adaption. In line with this expectation, the results from the regression PROCESS macro indicated that self-esteem acts a partial mediator between the variables. The finding essentially reflects that self-efficacy has both direct and indirect impacts on sociocultural adaption. Individuals' high selfefficacy increases their sense of positive self-regard and, consequently, positively impacts sociocultural adjustment. It is plausible that students' keen sense of belief in their capability to effectively deal with adjustment issues as a value can help them to appreciate themselves. This self-worth can, in turn, foster their ability to better respond to the environmental demands and fit into the host culture. Despite the paucity of studies on the mediating role of self-esteem, some general studies delineate that self-esteem mediates the relationship between social and academic adjustment outcomes (e.g., Nordstrom et al., 2014).

Given the paucity of literature on the role of individual difference domains on sociocultural adaptation (Wilson, 2013), findings of the study contribute to a better understanding of the nature of the relationship between individual factors of selfesteem and self-efficacy with sociocultural adaptation. More importantly, the mediating role of self-esteem may extend our knowledge and understanding of the relationship between predictors and adjustment outcomes. Apart from the theoretical contribution, findings of the study may also apply to university communities. The present finding that students' high self-efficacy, self-esteem, and travel experience positively contribute to adjustment may remind university communities to make concrete plans to cultivate and develop these psychological resources for their students. For instance, host institutions could organize different campus co-curricular activities like language and culture tutorial classes, cultural exhibitions, and sports competitions where both international and domestic students actively participate and attain a sense of pride and confidence. International students can also develop and maintain close cultural and social ties with people of different cultures which, in turn, facilitates their sociocultural adaptation. 
Furthermore, university communities could encourage and award international students who demonstrate outstanding academic and co-curricular performance so that belief in their capability can be enhanced. Arranging trips or excursions outside the campus can also increase the cultural orientation of international students in the host society. In addition, teachers of international students need to be aware of the individual difference factors such as self-efficacy and self-esteem and consider these in their instructional approach. Lecturers should also design their classroom environment in a way that students can actively participate and evaluate the teachinglearning process, and thus enhance their self-efficacy, positive self-image, and sociocultural adaptation.

Despite the contributions, there are some limitations to the present study that future studies might address. One potential limitation is that the study explored the relationships between the study variables based on correlational evidence rather than experimental evidence. In addition, since a questionnaire was applied to gather the sample data, flawed responses of the respondents might affect the accuracy of the findings. Another potential limitation is the sampling strategy. Convenience sampling was employed to select the sample. However, this sampling strategy might limit the degree of generalizability and representation of the population. Hence, in order to have a comprehensive insight into the issue of adjustment, future research studies might make a plan to adopt other research approaches such as a quasi-experiment, longitudinal study or mixing quantitative and qualitative research designs while using a large and representative sample.

\section{CONCLUSION}

Several personal and situational factors are presumed to qualify students' sociocultural adjustment in the host society. In line with this assumption, the present study attempted to identify the predictors of sociocultural adjustment for international students studying in China. Findings demonstrate that students' prior travel experience, self-efficacy, and self-esteem were observed to be good predictors. Moreover, the study reveals that self-esteem partially mediates the relationship between self-efficacy and sociocultural adaptation. Although the situational variables explain the sociocultural adaptation better, findings of the study point out that both situational variables of prior travel experience and individual difference factors of self-efficacy and self-esteem have a great contribution to students' positive sociocultural adjustment outcomes.

\section{REFERENCES}

Ang, S., \& VanDyne, L. (2008). Handbook of cultural intelligence: Theory, measures and applications. M.E. Sharpe.

Baldwin, M. W., Baccus, J. R., \& Fitzsimons, G. M. (2004). Self-esteem and the dual processing of interpersonal contingencies. Self and Identity, 3(2), 81-93. doi:10.1080/13576500342000068 
Bandura, A. (1995). Exercise of personal and collective efficacy in changing societies In A. Bandura (Ed.), Self-efficacy in changing societies (pp. 1-45). Cambridge University Press.

Bandura, A. (1997). Self-efficacy: The exercise of control. W.H. Freeman and Company.

Baron, R. M., \& Kenny, D. (1986). The moderator-mediator variable distinction in social psychological research: Conceptual, strategic, and statistical considerations. Journal of Personality and Social Psychology, 51(6), 11731182. http://dx.doi.org/10.1037/0022-3514.51.6.1173

Berry, J. W. (1997). Immigration, acculturation, and adaptation. Applied Psychology: An International Review, 46(1), 5-34. doi:10.1111/j.1464-0597.1997.tb01087.x

Black, S. J., Mendenhall, E. M., \& Oddou, G. (1991). Toward a comprehensive model of international adjustment: An integration of multiple theoretical perspective. The Academy of Management Review, 16(2), 291-317. doi:10.2307/258863

Bosson, J., \& Swann, W. B., Jr. (2009). Self-esteem: Nature, origins, and consequences. In R. H. M. Leary (Ed.), Handbook of individual differences in social behavior (pp. 527-546). Guilford.

Brisset, C., Safdar, S., Lewis, J. R., \& Sabatier, C. (2010). Psychological and sociocultural adaptation of university students in France: The case of Vietnamese international students. International Journal of Intercultural Relations, 34(4), 413-426. https://doi.org/10.1016/j.ijintrel.2010.02.009

Deci, E. L., \& Ryan, R. M. (1995). Human autonomy: The basis for true self-esteem In M. H. Kernis (Ed.), Efficacy, Agency, and Self-Esteem (pp. 31-49). Springer.

Dong, Q., Koper, R. J., \& Collaço, C. M. (2008). Social intelligence, self-esteem, and intercultural communication sensitivity. Intercultural Communication Studies XVII: 2 2008, 162-172.

Dzansi, D. Y., \& Monnapula-mapesela, M. (2012). An analysis of the adjustment problems of international students in a South African university. Journal for New Generation Sciences, 10(3), 28-49.

Garcia, M. S. S. (2015). The socio-cultural adaptation, openness to culture and success ofsojourn of foreign (Japanese) students in Tarlac City, Philippines. Proceedings of the Second Asia-Pacific Conference on Global Business, Economics, Finance and Social Sciences (AP15Vietnam Conference). ISBN: 978-1-63415-833-6 (Paper ID: V517). http://globalbizresearch.org/Vietnam Conference/pdf/V517.pdf

Gebhard, J. G. (2012). International students' adjustment problems and behaviors. Journal of International Students, 2(2), 184-193.

George, D., \& Mallery, P. (2003). SPSS for Windows step by step: A simple guide andreference. 11.0 update (4th ed.). Allyn \& Bacon.

Goldstein, S. B., \& Kim, R. I. (2006). Predictors of US college students' participation in study abroad programs: A longitudinal study. International Journal of Intercultural Relations, 30(4), 507-521. doi:https://doi.org/10.1016/j.ijintrel.2005.10.001

Gravetter, F., \& Wallnau, L. (2014). Essentials of statistics for the behavioral sciences (8th ed.). Wadsworth. 
Hajloo, N. (2014). Relationships between self-efficacy, self-esteem and procrastination in undergraduate psychology students. Iranian Journal of Psychiatry and Behavioral Sciences, 8(3), 42-49.

Hechanova-Alampay, R., Beehr, T. A., Christiansen, N. D., \& Van Horn, R. K. (2002). Adjustment and strain among domestic and international student sojourners: A longitudinal study. School Psychology International, 23(4), 458474. doi: $10.1177 / 0143034302234007$

Jex, S. M., \& Britt, T. W. (2008). Organizational psychology: A scientist-practitioner approach (2nd ed.). John Wiley and Sons.

Kernis, M. H. (2003). Toward a conceptualization of optimal self-esteem. Psychological Inquiry, 14(1), 1-26.

Koch, E. J. (2002). Relational schemas, self-esteem, and the processing of social stimuli. Self and Identity, 1(3), 271-279. doi:10.1080/152988602760124883

Li, A., \& Gasser, M. B. (2005). Predicting Asian international students' sociocultural adjustment: A test of two mediation models. International Journal of Intercultural Relations, 29(5), 561-576. https://doi.org/10.1016/j.ijintrel.2005.06.003

Liu, Y., Chen, X., Li, S., Yu, B., Wang, Y., \& Yan, H. (2016). Path analysis of acculturative stress components and their relationship with depression among international students in China. Stress and Health, 32(5), 524-532. doi:10.1002/smi.2658

Masgoret, A. M., \& Ward, C. (2006). The cultural learning approach to acculturation In W. J. Berry \& L. D. Sam (Eds.), The Cambridge handbook of acculturation psychology (pp. 58-77). Cambridge University Press.

Mesidor, J. K., \& Sly, K. F. (2016). Factors that contribute to the adjustment of international students. Journal of International Students, 6(1), 262-282.

Mustaffa, C. S., \& Ilias, M. (2013). Relationship between students adjustment factors and cross-cultural adjustment: A survey at the Northern University of Malaysia. Intercultural Communication Studies, 1(2013), 279-300.

Ngwira, F. F., Mapoma, H. W. T., Hong, J., Sariyo, S., \& Kondowe, W. (2015). Intercultural communication competence and acculturation among international students in Central China. Intercultural Communication Studies 2015, XXIV(2), $61-83$.

Nordstrom, A. H., Goguen, L. M. S., \& Hiester, M. (2014). The effect of social anxiety and self-esteem on college adjustment, academics, and retention. Journal of College Counseling, 17(1), 48-63. https://doi.org/10.1002/j.21611882.2014.00047.x

Padilla, A. M., \& Perez, W. (2003). Acculturation, social identity, and social cognition: a new perspective. Hispanic Journal of Behavioral Sciences, 25(1), 35-55. doi:10.1177/0739986303251694

Poyrazli, S., Arbona, C., Nora, A., McPherson, R., \& Pisecco, S. (2002). Relation between assertiveness, academic self-efficacy, and psychosocial adjustment among international graduate students. Journal of College Student Development, 43(5), 632-642.

Rosenberg, M. (1965). Society and the adolescent self-image. Princeton University Press. 
Schwarzer, R. (1992). Self-efficacy: Thought control of action. Hemisphere.

Schwarzer, R., \& Jerusalem, M. (1995). Generalized self-efficacy scale. In S. W. J. Weinman \& M. Johnston (Ed.), Measures in health psychology: A user's portfolio. Causal and control beliefs (pp. 35-37). NFER-NELSON.

Searle, W., \& Ward, C. (1990). The prediction of psychological and sociocultural adjustment during cross-cultural transitions. International Journal of Intercultural Relations, 14(4), 449-464. https://doi.org/10.1016/01471767(90)90030-Z

Smith, R. A., \& Khawaja, N. G. (2011). A review of the acculturation experiences of international students. International Journal of Intercultural Relations, 35(6), 699-713. https://doi.org/10.1016/j.ijintrel.2011.08.004

Sternberg, R. J., \& Vroom, V. (2002). The person versus the situation in leadership. The Leadership Quarterly, 13(3), 301-323. https://doi.org/10.1016/S10489843(02)00101-7

Tchoh, B. K., \& Mertan, E. B. (2018). Understanding the relationship between selfconstruals, self-esteem, social support, and the sociocultural adaptation of African students in Northern Cyprus. Journal of International Students, 8(2), 795-820. doi:10.5281/zenodo.1250381

Telbis, N. M., Helgeson, L., \& Kingsbury, C. (2014). International students' confidence and academic success. Journal of International Students, 4(4), 330 341.

Wang, K., T., Wei, M., Zhao, Chuang, C.-C., \& Li, F. (2014). The cross-cultural loss scale: Development and psychometric evaluation. Psychological Assessment, 27(1), 42-53. doi:10.1037/pas0000027

Ward, C., Bochner, S., \& Furnham, A. (2005). The psychology of culture shock. Routledge.

Ward, C., \& Kennedy, A. (1994). Acculturation strategies, psychological adjustment, and sociocultural competence during cross-cultural transitions. International Journal of Intercultural Relations, 18(3), 329-343. doi:10.1016/01471767(94)90036-1

Ward, C., \& Kennedy, A. (1999). The measurement of sociocultural adaptation. International Journal of Intercultural Relations, 23(4), 659-677. https://doi.org/10.1016/S0147-1767(99)00014-0

Ward, C., \& Rana-Deuba, A. (1999). Acculturation and adaptation revisited. Journal of Cross-Cultural Psychology, 30(4), 422-442. doi:10.1177/0022022199030004003

Wen, W., Hu, D., \& Hao, J. (2018). International students' experiences in China: Does the planned reverse mobility work? International Journal of Educational Development, 61, 204-212. https://doi.org/10.1016/j.ijedudev.2017.03.004

Wilson, J. K. (2013). Exploring the past, present, and future of cultural competency research: The revision and expansion of the sociocultural adaptation construct [Unpublished Doctoral Dissertation, Victoria University of Wellington]. https://core.ac.uk/download/pdf/41338074.pdf

Yang, R. P. J., Noels, K. A., \& Saumure, K. D. (2006). Multiple routes to crosscultural adaptation for international students: Mapping the paths between selfconstruals, English language confidence, and adjustment. International Journal 

of
Intercultural
Relations,
$30(4)$,
$487-506$.

https://doi.org/10.1016/j.ijintrel.2005.11.010

Yu, B., \& Wright, E. (2016). Socio-cultural adaptation, academic adaptation and satisfaction of international higher degree research students in Australia. Tertiary Education and Management, 22(1), 4964. doi:10.1080/13583883.2015.1127405 Yusoff, Y. M. (2011). International students' adjustment in higher education: relation between social support, self-efficacy, and socio-cultural adjustment. Australian Journal of Business and Management Research, 1(1), 1-15.

Zhang, J., \& Goodson, P. (2011). Acculturation and psychosocial adjustment of Chinese international students: Examining mediation and moderation effects. International Journal of Intercultural Relations, 35(5), 614-627. https://doi.org/10.1016/j.ijintrel.2010.11.004

WEREDE GEBREGERGIS, MSc in Applied Psychology, is a lecturer in the Department of Psychology, Asmara College of Education, Eritrea and former master's student at Central China Normal University. His research interests include employees work commitment, satisfaction and performance; employees' psychological and organizational empowerment; positive organizational behavior; stress, coping, and burnout at work place; and international students' adjustment issues, mental health issues, and educational studies.

E-mail: weredetarekeg@yahoo.com

DESBELE MEHARI is an assistant lecturer in the Department of Educational Administration, Asmara College of Education, Eritrea. Currently, he is pursuing his master's degree in Comparative Education at Central China Normal University. His research interests include comparative education, students' learning motivation, educational leadership and management, international students' adjustment issues, students' special educational needs, child and maternal care, and child development. E-mail: desbeletekie1983@gmail.com

DAWIT GEBRETINSAE is an assistant lecturer in the Department of Psychology, Asmara College of Education, Eritrea. Currently, he is pursuing his master's degree in Applied Psychology at Central China Normal University. His research interests include stress and coping, self-determination and motivation, international students' adjustment issues, teaching and learning, students' special educational needs, and child and adolescent development. E-mail: dawityikealo@gmail.com

ASTER TESFAMARIAM, MEd in Educational Management and Economics, is a lecturer in the Department of Educational Administration, Asmara College of Education, Eritrea and former master's student at Central China Normal University. Her research interests include students' learning motivation, educational leadership and management, cross-cultural studies, learner-centered and interactive pedagogy, and gender and education. E-mail: asterhabteeit@gmail.com 